\title{
DE RÁDIOS A REDES COMUNITÁRIAS? REFLEXÕES SOBRE OS NOVOS CAMINHOS TECNOPOLÍTICOS DA COMUNICAÇÃO COMUNITÁRIA
}

\author{
From radios to community networks? \\ Reflections on the new technopolitical ways of community communication
}

\author{
De radios a redes comunitarias? \\ Reflexiones sobre los nuevos caminos tecnopolíticos de la comunicación \\ comunitaria
}

João Paulo Malerba

Professor substituto da UERJ e pesquisador do Laboratório de Estudos em Comunicação

Comunitária da UFRJ

joaopaulomalerba@gmail.com

\section{Resumo}

$\mathrm{O}$ artigo analisa as mudanças tecnológicas e políticas que têm afetado as mídias comunitárias no contexto dos desafios da convergência midiática e da hegemonia de um novo modo de ação política que contrasta com o modo como originalmente se conformaram tais atores. Tendo como objeto de estudo as transformações nos modos de ser das rádios comunitárias, são discutidos os descompassos, desafios e adaptações tecnopolíticas do encontro desses antigos atores sociais com a comunicação em rede. $\mathrm{O}$ artigo se vale de pesquisas bibliográfica, documental e conceitual; observação-participante; entrevistas semiestruturadas; além de duas pesquisas empíricas interdependentes no intuito de contribuir para o campo da Comunicação Comunitária desde a análise do desenvolvimento político e tecnológico de seu objeto.

Palavras-chave: Comunicação Comunitária. Rádios Comunitárias. Redes Comunitárias.

\begin{abstract}
The article analyses the technological and political changes that have affected the community media in the context of the challenges of media convergence and the hegemony of a new mode of political action that contrasts with the way in which these actors were originally formed. Having as object of study the transformations in the modes of being of the community radios, the disruptions, challenges and technopolitical adaptations of the encounter of these former social actors with the network communication are discussed. The article uses bibliographical, documentary and conceptual research; observation-participant; semi-structured interviews; in addition to two empirical interdependent researches in order to contribute to the field of Community Communication since the analysis of the political and technological development of its object.
\end{abstract}

Key words: Community Communication. Community radios. Community networks.

\section{Resumen}


El artículo analiza los cambios tecnológicos y políticos que han afectado a los medios comunitarios en el contexto de los desafíos de la convergencia mediática y la hegemonía de un nuevo modo de acción política que contrasta con la forma en que originalmente se formaron estos actores. Teniendo como objeto de estudio las transformaciones en los modos de ser de las radios comunitarias, se discuten las disrupciones, los desafíos y las adaptaciones tecnopolíticas del encuentro de estos antiguos actores sociales con la comunicación de red. El artículo utiliza investigación bibliográfica, documental y conceptual; observador participante; entrevistas semi-estructuradas; además de dos investigaciones empíricas interdependientes para contribuir al campo de la Comunicación Comunitaria desde el análisis del desarrollo político y tecnológico de su objeto.

Palabras clave: Comunicación comunitaria. Radios comunitarias. Redes comunitarias.

\section{INTRODUÇÃO}

A estruturação do campo de pesquisa que, no Brasil, atualmente convencionamos nomear Comunicação Comunitária tem se dado pari passu ao desenvolvimento de seu próprio objeto. Tradicionalmente, tal área se dedica à reflexão de iniciativas comunicacionais voltadas para a reivindicação de direitos, que visam o reequilíbrio das forças políticas e que são levadas a cabo por comunidades geográficas, étnicas e de interesse. Desde as reflexões embrionárias, seus teóricos e pesquisadores têm focado nos aspectos educativos, mobilizadores e transformadores de um modo de fazer comunicação que se propõe mais horizontal, participativo e democrático e que, com isso, possa vir a se contrapor a desigualdade de acesso que caracteriza a maioria dos cenários midiáticos e a instaurar mais justiça social. Nesse sentido, seus objetos mais caros de análise têm sido as apropriações que, principalmente, movimentos sociais e comunitários fazem das mais diferentes mídias em favor de suas demandas. Por conseguinte, tal foco acaba por privilegiar normalmente usos mais politizados dos meios de comunicação por parte de coletivos e setores organizados da chamada esquerda do espectro político.

Há quem localize o surgimento das mídias comunitárias em meados do século XX, na América Latina, quando era mais comum nomeá-las populares e alternativas. Foi quando, uma ala mais progressista da Igreja Católica protagonizara - frequentemente junto aos governos nacionais em seus projetos modernizadores - um processo de alfabetização, educação e evangelização através das escolas radiofônicas, especialmente em comunidades rurais e nas periferias das grandes cidades. Paralelamente, vivíamos um processo de complexificação da sociedade civil latino-americana, resultante também do desenvolvimento de nosso capitalismo industrial tardio: dentre tantas organizações, alguns sindicatos e partidos políticos iam incidindo em uma esfera pública em plena formação, na cidade e no campo. 
Nesse contexto, para os setores populares, a criação de meios de comunicação próprios configurava-se como peça-chave na disputa pelo consenso. Enquanto o alcance da mídia impressa era suficiente para a concentração humana das cidades e de suas fábricas, nas áreas rurais e amazônicas o rádio se forjava como o meio mais eficiente por conta da dispersão populacional. As ditaduras que varreriam o subcontinente a partir de uma década depois só intensificariam o processo de fortalecimento - e repressão - da mídia popular, além de acelerar a apropriação daquelas escolas radiofônicas em favor da mobilização política. Também as classes médias urbanas se organizariam em veículos próprios de resistência, normalmente apoiadas no jornalismo profissional, a também chamada no Brasil de imprensa alternativa. Porém, quando falamos de meios comunitários nos referimos às iniciativas de comunicação das classes populares e seus aliados, como universidades, sindicatos, cooperação internacional, Igreja Católica, entre outros, em seu processo de organização política e de resistência.

Esse momento de formação do campo está muito marcado por uma relação orgânica com um macroprojeto político comum e bem definido. As mídias comunitárias tradicionais conformaram-se ao modelo de uma estrutura que pressupunha um caminho para a transformação social e que requeria a unificação e organização da ação política em torno de um mesmo objetivo. Novas causas e pautas eram bem-vindas, desde que representassem demandas sociais reais e se auto-reconhecessem naquele horizonte comum. Desse modo, a luta política não podia abrir mão de alguma hierarquia e centralidade para garantir a unidade tida como necessária. Para que tal sistema representativo funcionasse, acabava sendo inevitável a conformação de líderes que, além de personificar a dedicação e os princípios modelares para a luta, garantiria a unidade pretendida. Outro elemento era a conquista do Estado como fim: na prática, isso significava o comando democrático do poder desde as menores células organizativas, incluídas aí os meios comunitários.

A partir da década de 1980, o fim da ditadura civil-militar, a intensificação da urbanização, a diversificação de nossa sociedade civil, os anos de neoliberalismo e o aparecimento de novas tecnologias comunicacionais seriam alguns fatores que incidiriam diversas mudanças nos meios comunitários.

Em sua análise da evolução terminológica no campo, Peruzzo (2008) atesta que seria nos anos 1990 a consolidação do termo mídia comunitária, "ou seja, seu sentido menos politizado", em que, "às vezes se desconecta de movimentos sociais e assume feições diversificadas quanto às bandeiras defendidas e mensagens transmitidas" (p. 368, grifo meu). 
A pesquisadora verifica que tal mudança pode vir a dar conta de outros perfis sociais e políticos:

Comunicação comunitária, na forma como vem se desenvolvendo nos últimos tempos significa: o canal de expressão de uma comunidade (independente do seu nível socioeconômico e território), por meio do qual os próprios indivíduos possam manifestar seus interesses comuns e suas necessidades mais urgentes [além de, paralelamente, vir a] incorporar as novas tecnologias de informação e comunicação (NTIC) com todo seu potencial e exigências (p. 371).

\section{MUDANÇAS TECNOPOLÍTICAS NAS MÍDIAS COMUNITÁRIAS}

A incorporação das novas tecnologias de comunicação por meios comunitários (como webrádios comunitárias, jornais comunitários online, podcasts de ativistas etc.) significa mais que a mera continuidade no mundo digital. Partindo da compreensão de que mídias comunitárias são, antes de tudo, atores políticos (MALERBA, 2016) ${ }^{1}$, uma análise interessada nas raízes e consequências de tais transformações deve focar na totalidade tecnopolítica das mudanças, relacionando-as ao momento político atual e às recentes disputas em torno da convergência midiática.

Primeiramente, suas transformações devem ser compreendidas à luz das presentes crises do modelo de democracia representativa e da esquerda, notadamente, no caso latinoamericano. Isso é particularmente relevante para atores que têm seu modelo, em maior ou menor medida, emprestados de uma matriz política-organizativa que agora é posta em xeque após ter-se demonstrado porosa aos jogos corruptores de poder e a alianças que resultaram no abandono de algumas de suas bandeiras históricas. As particularidades desse processo, no contexto latino-americano, fizeram-se sentir mais intensamente a partir dos anos 2000, com a guinada à esquerda nos governos da maioria dos países do nosso subcontinente. Ainda que, em certa medida, isso só fora possível pelo engajamento político dos próprios meios comunitários, parcela importante dos movimentos de base dos partidos alçados ao poder, os

\footnotetext{
${ }^{1}$ Para além de instituições formais ou sujeitos coletivos, nosso entendimento de ator político abrange todas essas novas formas e estratégias de ação política inauguradas e fomentadas pelas recentes mutações sociais e tecnológicas. De todo modo, analógicas ou digitais, locais ou em rede, afetivas ou racionais, fruto de iniciativas individuais ou orquestrações coletivas, a elasticidade do conceito de ação política não está na multiplicidade de suas manifestações, mas no fato ontológico de que "todas as esferas do ser social são atravessadas pela política, contêm a política como elemento real ou potencial ineliminável" (GRAMSCI, 2001, v.3, p. 91). A natureza do ato político permanece inalterada: "a elaboração superior da estrutura em superestrutura na consciência dos homens" (p. 314) e que leva a uma postura ativa frente ao processo histórico e se concretiza em atos motivados por um dever-ser, com o objetivo de deslocar as relações de poder na sociedade.
} 
governos nacionais tidos de esquerda não responderam às expectativas por democracia na comunicação.

Entre nós não foi verificada relação automática entre governos de esquerda e avanços legais em favor da efetivação do direito à comunicação, como conclui Gustavo Gomez, diretor do uruguaio Observatório Latinoamericano de Regulación, Medios y Convergencia, num recente balanço (2016) das políticas de comunicação dos governos do Cone Sul. No caso do Paraguai, Lugo (2008-2012), não fez mais que alavancar alguns poucos meios públicos, sem medida efetiva para democratizar a mídia; no Chile, os sucessivos governos da Concertación (1990-2010) e Nueva Mayoría (2013-2018) nunca se comprometeram com a causa, a exemplo da péssima lei de radiodifusão comunitária (2010); os governos uruguaios do Frente Amplio (2005-atual), mesmo com o mérito da exemplar lei de radiodifusão comunitária (2007), mantiveram intacto o oligopólio televisivo; na Argentina, a judicialização promovida pelo grupo Clarín e, principalmente, a parca aplicação da emblemática Ley de Medios não consolidou suas conquistas a ponto de protegê-la dos ataques de Macri; no caso do Brasil, o governo do Partido dos Trabalhadores (2002-2016) viu seu pacto de pax conservadora com os meios hegemônicos voltar-se contra si.

Tais contradições têm afetado os meios comunitários desde a base, comprometendo sua relevância no conjunto da sociedade civil, enfraquecendo sua influência nas comunidades e nublando seu horizonte de luta. Acreditamos, porém, que, além das conjunturas políticas domésticas, há um deslocamento estrutural na ação política contemporânea que sobredetermina tais conjunturas e é por elas sobredeterminado. Como bem demonstram Hardt e Negri (2001; 2012), atualmente vemos a emergência de um sujeito político historicamente novo, que tem na comunicação, cooperação e na colaboração a base organizativa de seu modo de ação. Os autores dão o nome de multidão a essa coletividade de sujeitos que não forma uma identidade coletiva, nem a busca: suas inúmeras diferenças e desejos não podem ser reduzidos a uma unidade ou identidade única. Por isso, há um desafio constante em fazer com que tal multiplicidade social (entendida como imprescindível para sua força) consiga se comunicar e agir em comum. Há rejeição a qualquer tipo de soberania, hierarquia e representatividade. Seu modo de ação se adéqua mais a uma espiral por se basear na pluralidade contínua de seus elementos e redes de comunicação, e tem na mobilização de afetos a principal estratégia de ação política. A institucionalidade não é necessária e o seu projeto político é não teleológico. Se se vislumbra um projeto comum de seus sujeitos, ele é imanente e se mantém com base no que compartilham e produzem em comum. Ainda que se 
trate de um sujeito político emergente e cujas condições de ação continuam a ser forjadas, sua iminente hegemonia já se faz entrever em contextos políticos reais: por exemplo, no caso brasileiro, as chamadas Jornadas de Junho de 2013 são paradigmáticas pelas características difusas de suas pautas, o modo como sua ação foi organizada e a dificuldade em categorizar seus sujeitos. Ainda que tenham começado em São Paulo por conta do aumento das tarifas de transporte, as manifestações rapidamente se espalharam pelo Brasil atingindo cerca de 400 cidades, 12 capitais (PERUZZO, 2013, p. 74) e uma diversidade de reivindicações. Pelo que já sabemos daquele fenômeno ainda não totalmente decifrado ${ }^{2}$, sua mobilização não parece ter sido por rádios comunitárias, imprensas sindicais ou congêneres, mas através da tecnointeração afetiva, fluida e efêmera das redes sociais por parte de movimentos juvenis urbanos.

Hoje, a ação política tem na comunicação em rede sua plataforma por excelência e as disputas sociais e políticas estão inseparáveis e atravessadas por disputas tecnológicas. E isso se deve a, pelo menos, dois motivos: um de natureza político-social, o outro, de natureza econômica. A disputa de ideias - que é a verdadeira razão de ser das mídias comunitárias - é mais e mais protagonizada nas redes sociais, listas de e-mails, através de celulares, de aplicativos de mensagens instantâneas: as vozes e visões minoritárias têm que passar (também) por aí se quiserem continuar vivas nesse novo tecido político-social ou, ao menos, dialogar com estes espaços. Acontece que não somente os acordos sociais e políticos passam pela estrutura da rede: ela é hoje a própria infraestrutura de produção de valor e riqueza na sociedade. É quando chegamos à natureza econômica das atuais disputas tecnológicas: o controle da infraestrutura da rede passa a estar no centro de uma disputa de dimensões gigantescas.

No caso dos meios comunitários, seus tradicionais oponentes eram definidos e delimitados pela disputa política e social doméstica: o Estado nacional, que reprimia e negava direitos; as oligarquias locais e regionais, que deslegitimava socialmente as mídias comunitárias; as empresas nacionais de comunicação, em sua ânsia capitalista pelo monopólio e lucro. Hoje, aos habituais opositores nacionais, somam-se as corporações transnacionais de telecomunicações e blocos/acordos econômicos que buscam privatizar até a última faixa de frequência do espectro eletromagnético.

\footnotetext{
${ }^{2}$ Há autores que apontam o papel que a mídia hegemônica desempenhou na reinterpretação e deslocamento das pautas originais das Jornadas de 2013 em direção a temas conservadores. Isso já aparece em análises imediatamente posteriores (SINGER, 2013; MARICATO et al, 2013), mas é detalhadamente delineado por Jardim Pinto (2017).
} 
Enquanto corporações transnacionais, as empresas de telefonia pressionam os Estados a gerenciar os ambientes nacionais de mercado aos interesses de seu lucrativo negócio, em plena expansão justamente por oferecerem a infraestrutura do maquinário que produz o bem de maior valor agregado no estágio atual do capitalismo: comunicação. Ainda que a infraestrutura da telefonia dependa de um complexo coordenado de tecnologias (satélites, fibras óticas, cabos submarinos etc.), a atual imprescindibilidade da comunicação instantânea e ubíqua dos dispositivos móveis aumenta o apetite das teles pelo uso monopolístico do ar. Isso porque, assim como rádio e TV, a telefonia celular faz uso do espectro eletromagnético para o tráfego de dados. A faixa inicialmente reservada para o serviço foi insuficiente e novas alocações já estão no limite, dado o crescimento exponencial do setor (devido principalmente à demanda por internet sem fio) e da necessidade de tecnologias de transmissão mais eficientes.

Nesse cenário, não basta que as mídias comunitárias tradicionais se adaptem ou meramente migrem para a infraestrutura da rede: nesse novo horizonte de disputa com poderosos players do capitalismo internacional, o novo desafio das comunidades em luta pelo direito humano à comunicação está em ocupar e apropriar-se dos códigos e ferramentas da infraestrutura da rede, se quiserem reverter seu processo de privatização.

\section{DESCOMPASSOS, DESAFIOS E ADAPTAÇÕES TECNOPOLÍTICAS DAS RÁDIOS COMUNITÁRIAS}

Em nossa pesquisa de doutorado, Rádios comunitárias no limite: crise na política e disputa pelo comum na era da convergência midiática (MALERBA, 2016), perseguimos a hipótese de uma crise estrutural nas rádios comunitárias brasileiras. Para tal, foram realizadas pesquisas bibliográfica, documental e conceitual; observação-participante do movimento latino-americano pelo direito à comunicação; entrevistas semiestruturadas com pesquisadores em Comunicação Comunitária; além de duas pesquisas empíricas interdependentes: uma investigação quantitativa, via questionário estruturado, com cem rádios comunitárias ${ }^{3}$ de diversos tipos das cinco regiões do Brasil, amparada por pesquisa qualitativa com estudo de caso de dez dessas emissoras ${ }^{4}$, de inspiração etnográfica. Dos extensos resultados obtidos,

\footnotetext{
${ }^{3}$ Assim distribuídas: Norte: 11; Nordeste: 34; Centro-Oeste: 11; Sudeste: 26; Sul: 18.

${ }^{4}$ Solicitamos indicações de pesquisadores e militantes quanto a rádios consideradas autênticas, particularistas (motivação político-partidária, religiosa, comercial etc.) e inovadoras (webrádio, podcasts etc.). A partir daí, selecionamos dez rádios emblemáticas e de diferentes tipos (livres, outorgadas, webrádio), origens (sindicatos rurais, grupos partidários, Igreja, universidades) e contextos (grandes centros urbanos, Amazônia, assentamento
} 
iremos resumidamente nos ater aqui às principais descobertas nos âmbitos políticoorganizativo e tecnológico a fim de analisar os desafios - e as respostas - das rádios comunitárias frente às transformações da/o ação/sujeito política/o contemporânea/o e da comunicação em rede.

No âmbito político-organizativo nossa conclusão é de que as rádios comunitárias ainda estão muito marcadas pelos modos de ser e de ação política da "esquerda tradicional", que influenciaram a origem individual de muitas delas e do movimento social que as representa, acarretando numa estrutura organizativa de tendência mais vertical e disciplinar. Um dos indícios é a procedência político-partidária de boa parte de seus militantes: na pesquisa qualitativa com 10 emissoras, isso pode ser verificado em, ao menos, seis delas. Foram naquelas agremiações que as rádios comunitárias primeiro encontraram acolhida à sua causa e, principalmente, era lá que militava boa parte de seus comunicadores e de lá extraíram seu modo de organização. Outro sinal de tal influência confirma tanto a natureza política das rádios comunitárias quanto sua simpatia ao sistema representativo: uma em cada 4 rádios confirma a candidatura de algum dirigente e/ou locutor nas últimas eleições. Indo além, muitas rádios surgem para a disputa político-partidária principalmente contra poderes locais estabelecidos por partidos de direita, como atestamos na Esperança, Terra Livre e Quixelô FM.

Nossa compreensão é de que isso tem significado um descompasso com a hegemonia de ação política da atualidade, menos afeita a estrutura usual das rádios comunitárias (de tendência representativa, hierárquica, centralizada), cada vez menos atraentes para a militância contemporânea. Dentre outros motivos, o resultado tem sido uma participação cada vez menor da comunidade, ainda que isso seja, desde sempre, um elemento definidor da mídia comunitária: quando perguntados, quase três em cada quatro (73\%) respondentes da pesquisa quantitativa afirmam sentir dificuldade para atrair novos colaboradores para a rádio. Mergulhando nesse aspecto, nossa pesquisa qualitativa identificou nas rádios uma diversidade de sistemas decisórios, mas com a tendência comum de buscar instâncias e modos mais participativos de decisão, fruto de uma cultura interna de valorização da participação. Porém, na prática, o que percebemos nas pesquisas qualitativa e quantitativa é uma baixa presença da comunidade: somente uma entre cada quatro rádios menciona a participação da comunidade

rural). São elas: Norte: Rádio Xibé (Tefé/AM) e Rádio Cidade FM (Altamira/PA); Nordeste: Rádio Independência FM (Independência/CE), Rádio Esperança FM (Queimada Nova/PI) e Rádio Quixelô FM (Quixelô/CE); Sudeste: Rádio Muda (Campinas/SP) e Rádio Heliópolis (São Paulo/SP); Sul: Webrádio AlmA (Londrina/PR) e Rádio Terra Livre (Abelardo Luz/SC); Centro-Oeste: Rádio Utopia FM (Planaltina/DF). 
nas reuniões da emissora. O resultado é um centralismo brando involuntário: a prática de democracia representativa legitimada pela pró-atividade, em que o grupo dos mais ativos acaba tendo um poder que quase nunca é questionado, em parte devido a pouca disponibilidade/ interesse dos demais participantes. De todo modo, não notamos nas rádios visitadas barreiras formais ou informais para participação da comunidade: é a comunidade que não parece muito interessada no cotidiano interno da rádio.

Outra consequência é a dificuldade em recrutar a juventude. Na pesquisa quantitativa verificamos que somente uma em cada quatro rádios (26\%) tem maioria jovem em sua equipe e o equilíbrio etário acontece em quase metade delas (46\%). Na pesquisa qualitativa verificamos militantes de todas as faixas etárias, inclusive em metade delas há forte presença de jovens (AlmA, Esperança, Utopia, Terra Livre e Muda), ainda que muitas delas reclamem de falta de renovação. Tais resultados híbridos são mais bem iluminados por quem tem uma visão regional e temporal desses atores políticos. Em entrevista para o autor, o ex-vicepresidente da Associação Mundial de Rádios Comunitárias - AMARC América Latina e Caribe, Carlos Aparício, observa que os jovens continuam, sim, nas rádios comunitárias, mas não em cargos representativos (APARICIO, 2015). Opinião parecida expressou Ernesto Lamas, ex-coordenador regional da AMARC América Latina e Caribe: ainda que haja jovens nas rádios, eles não se interessam em fortalecer uma rede, "não seduzimos mais para o movimento [de rádios comunitárias]" (LAMAS, 2015). O que tem afastado os jovens da vanguarda do movimento de rádios comunitárias não parece diferir do que os afasta dos partidos políticos, justamente seu modo de organização e ação política.

Ao que parece - e ao contrário do que um causalismo tecnológico poderia indicar não é por ser analógica que a rádio comunitária não seduz, como antes, a juventude. Até porque, no que se refere às novas tecnologias de informação e comunicação, os resultados da nossa pesquisa demonstraram razoável adaptação e apropriação por parte das rádios comunitárias.

Em se tratando de três importantes novos caminhos tecnológicos do rádio, identificamos avanços, riscos e resistências em um cenário ainda indeterminado. Dentre suas vantagens, a webrádio (rádio via internet) oferece às comunitárias a desterritorialização (da transmissão e da audiência) e um ambiente desregulamentado: frente a tais possibilidades, nossa pesquisa quantitativa indicou que três em cada quatro (76\%) emissoras já transmitem via web. Bem menos populares têm sido os podcasts (programas de rádio em formato digital, para recepção assincrônica), oferecidos por somente um terço (33\%) delas: vemos aí 
desperdiçadas possibilidades de estratégias para campanha e viralização de conteúdo via redes sociais. E quanto a digitalização do rádio, a maioria das rádios pesquisadas (60\%) afirma acompanhar as discussões sobre sua implementação, que tem sido encarada por muitos como uma revolução tecnológica no rádio e uma nova fronteira de disputa e possibilidade para as rádios comunitárias.

Ainda que quatro em cada cinco rádios contem com site próprio, em se tratando de comunicação em rede, as rádios comunitárias têm concentrado sua energia em ocupar as redes sociais, ainda que sua presença maciça (80\%) seja numa rede corporativa, não privativa e comercial como o Facebook. O seu principal uso tem se voltado para a divulgação de informações sobre a rádio e interação com o ouvinte, enquanto o debate político nas redes sociais foi mencionado por somente $2,5 \%$ das pesquisadas. Outra atitude de vanguarda se refere ao uso do celular, ator relevante na relação com os ouvintes e, em alguns casos, o principal recurso interativo, com usos bastante criativos. Surpreendeu notar que o aplicativo WhatsApp (quase 50\%) já ultrapassa as menções às ligações telefônicas (33\%) e aos SMS's (30\%), sendo usado para receber áudios, criar grupos de ouvintes e auxiliar na da gestão interna da rádio.

Para as rádios comunitárias a libertação dos softwares proprietários significa tanto a garantia de privacidade/segurança em seus dados (para atores normalmente envolvidos em embates contra os poderes estabelecidos) quanto o acompanhamento de importantes inovações tecnológicas da convergência midiática, sem ou com baixo custo. Os resultados de nossa pesquisa quantitativa revelam que os softwares livres estão presentes na maioria das rádios comunitárias $(71 \%)$ e em mais da metade delas $(54 \%)$ é maioria ou o único tipo de software utilizado (26\%). Por fim, quanto a atuação na apropriação e oferta de infraestrutura de rede as intenções estão dadas: $60 \%$ das rádios pesquisadas demonstraram interesse em se tornarem provedores de internet.

\section{RÁDIOS COMUNITÁRIAS NA DISPUTA EM REDE}

A criação de rede de rádios é uma estratégia antiga das rádios comunitárias. Basta lembrar que as primeiras rádios populares latino-americanas surgem de redes de rádios educativas que, individual ou coletivamente, vão adquirindo perfis políticos ao longo de seu processo histórico. Nessa linha, um exemplo é a combativa rede de rádios mineiras bolivianas. Mas há casos como o da irreverente Rede Totó Ternura (homenagem irônica a 
Antônio Carlos Magalhães, então ministro das Comunicações) na explosão das livres paulistanas, em meados dos anos 1980.

$\mathrm{O}$ advento da chamada web 2.0 permitiu a conformação de redes virtuais de rádios comunitárias caracterizadas por serem horizontais, colaborativas, multidirecionais e mais ou menos autônomas: é que tais redes virtuais dependem de uma plataforma que a deem suporte. Normalmente essa plataforma é um portal da internet específico, que se somam às inúmeras comunidades virtuais criadas em redes sociais genéricas (Facebook, Instagram, Twitter etc.). Além disso, já estamos vendo surgir redes virtuais que têm como suporte aplicativos multiplataforma de mensagens instantâneas via celular (como WhatsApp e Telegram).

Num estudo preliminar, em nossa pesquisa de mestrado (MALERBA, 2009) analisamos o Radiotube (http://radiotube.org.br), uma rede social de compartilhamento de material informativo - principalmente em áudio, a partir de podcasts - exclusivamente ligado à cidadania, que congrega via internet milhares de ativistas, estudantes, integrantes de rádios comunitárias, professores, entre outros mebros de diferentes partes do Brasil. Lançado em 2007 pela ONG de comunicação popular CRIAR Brasil, hoje o Radiotube congrega mais de 6 mil usuários. A partir da análise do seu último relatório (CRIAR BRASIL, 2016) que compila uma pesquisa realizada com os usuários do Radiotube, notamos que ele se tornou um importante nó temático em relação às demais redes: 83\% dos usuários fazem parte de alguma instituição afim, $85 \%$ compartilham o material em outras redes, sendo que $73 \%$ via Facebook.

Já no universo das rádios livres, o pioneirismo de uma rede virtual específica é do projeto http://radiolivre.org, que dá suporte técnico para que as livres transmitam online (webrádio), promovam trocas e realizem parcerias. A rede faz parte do chamado Rizoma de rádios livres, "uma colaboração (financeira, de conteúdo, assessoria jurídica, de equipamentos e servidor) entre as rádios livres" ou "uma rede de agenciamentos" que almeja conectar todas elas a partir de um portal e outros tipos de articulações, como lista de discussões via e-mail, ligações telefônicas, encontros nacionais periódicos, oficinas, etc.. Na eventualidade, por exemplo, de uma rádio ser fechada pela Anatel e Polícia Federal, ou de um problema técnico, ou no desejo de criação de uma nova emissora etc., "diversos são os arranjos dentro do Rizoma de Rádios Livres para que o problema seja resolvido, como comprar um novo transmissor em Campinas e enviar para o Pará, ou simplesmente receber instruções de como sintonizar um transmissor através do wiki” (GONÇALVES, 2010, p. 102).

No âmbito das redes sociais genéricas (com preponderância para o Facebook), as rádios comunitárias vão criando comunidades virtuais por afinidades e interesses ligados aos 
objetivos do projeto da rádio: com a própria comunidade de ouvintes e participantes; com associações e movimentos políticos de rádios comunitárias; com outras entidades e parceiros da sociedade civil; etc.. Mas, principalmente, a entrada das rádios comunitárias nas redes sociais tem se configurado como mais um espaço de interação e estratégia de vinculação interna e com a comunidade.

\section{REDES COMUNITÁRIAS NA DISPUTA PELA REDE}

Se nas redes virtuais as rádios comunitárias utilizam a plataforma da rede, com as redes comunitárias elas podem, simultaneamente, ser e compor a plataforma da rede. Ainda que, por ora, sejam poucas no Brasil, a aposta é que as comunidades venham a se apropriar mais e mais dessa infraestrutura de rede aberta, descentralizada e autogerida.

Essas redes normalmente utilizam a tecnologia da "transmissão de dados sem fio através da família de protocolos 802.11 (wifi | wireless) em equipamentos como roteadores, antenas e outros, aliados ao uso de programas de código aberto (softwares livres)"5, permitindo uma rede de dados veloz e de baixo custo. Quanto à interconexão, uma forma descentralizada e resistente é a em malha (mesh), em que a perda de um ponto não afeta a rede como um todo. Os roteadores ocupam hoje uma faixa do espectro que está dispensada de licenciamento. Com isso, essas redes começam a se espalhar pelo país garantindo acesso à banda larga sem fio em comunidades consideradas desimportantes para o mercado das operadoras de telecomunicações. Seus usos podem abranger desde uma rede interna entre nós conectados até a ampliação do acesso à internet através de um provedor comunitário.

Um exemplo de sucesso foi a implantação de redes comunitárias (internet e celular) na vila da Fumaça, no município de Resende, desenvolvida no hacklab rural Nuvem. A região não contava com telefones fixos (além de alguns telefones público com funcionamento irregular) e nem cobertura de celular, mesmo após vários abaixo-assinados feitos pelos moradores junto às operadoras de telecomunicações. A partir de um (desafiante) processo de articulação local conseguiu-se implantar um provedor de internet gratuito e uma estação de telefonia celular comunitária (GSM5), a partir de um mutirão de moradores, pesquisadores e ativistas (cf. VIANNA, 2017). Tal iniciativa teve como inspiração a iniciativa (já considerada emblemática) que viabilizou telefonia celular comunitária para 16 comunidades rurais ao redor do estado de Oaxaca, no México. Antes isoladas devido ao desinteresse comercial das

\footnotetext{
${ }^{5}$ Disponível em http://www.redeslivres.org.br/sobre/. Acesso em 4 de agosto de 2016.
} 
teles pela região, os cerca de três mil usuários dessas comunidades hoje contam com acesso à emissão e recepção de som e mensagem por aparelhos de celulares simples. A iniciativa do coletivo Rhizomática usa a tecnologia GSM e $2 \mathrm{G}$ para operar os sinais na rede de telefonia móvel. A experiência ganhou status legal depois da luta de rádios comunitárias e movimentos indígenas local para garantir o direito à concessão social do espectro eletromagnético. $\mathrm{O}$ pedido foi encaminhado às autoridades e concedido em caráter experimental por quinze anos (cf. DEISTER, 2017).

Esse novo paradigma na disputa pelo ar sublinha as muitas deficiências das regulamentações nacionais quanto ao uso do espectro eletromagnético e reacende a luta contra sua privatização. Assim, na luta pelo direito à comunicação os exemplos acima integram novas demandas tecnopolíticas que reivindicam o espectro como bem comum, incentivando práticas comunitárias de acesso à telefonia e às redes digitais e defendendo o chamado espectro livre. Tal movimento reivindica autonomia na gestão de uma parcela do que entende ser um patrimônio imaterial da humanidade. A defesa do espectro eletromagnético como bem comum integra um movimento mais amplo de defesa da gestão compartilhada de recursos (materiais e imateriais) por comunidades, baseada na cooperação e dependência mútua: os commons. Na prática, os defensores do espectro livre propõem o uso não licenciado e não comercial de partes de todas as faixas do espectro: ou seja, tanto um provedor de internet ou de telefonia celular quanto uma emissora de rádio ou TV. Refutando o usual argumento da escassez e da interferência, argumentam a novíssima situação de tecnologias (como rádio cognitivo e rádio definido por software) que partem do princípio de compartilhamento do espectro para proporcionar sua abundância.

\section{CONSIDERAÇÕES}

O atual presidente mundial da AMARC, o francês Emannuel Bouterin, por ocasião de sua eleição na $11^{\circ}$ Assembleia, realizada em Gana, em agosto de 2015, comenta dois deslocamentos mundiais, em sua opinião, centrais e contraditórios com relação às rádios comunitárias: uma onda legal mais favorável e outra de maior disputa pelo espectro eletromagnético por conta das empresas de telefonia.

A nosso ver não há contradição, mas, coerência e sincronia entre os dois movimentos. Como dissemos, os adversários das rádios comunitárias não são mais (somente) as oligarquias nacionais, em prováveis alianças com as corporações mundiais: agora, são as próprias 
corporações que entram na disputa. Com relação ao caso brasileiro, não parece ser coincidência que a privatista Lei Geral de Telecomunicações (LGT) tenha vindo antes (1997) da legislação de radiodifusão comunitária (1998) e de uma (ainda distante) nova lei geral de comunicação no Brasil. A aprovação da LGT e a consequente criação da Anatel significou a reestruturação do poder regulatório e repressor do Estado: apenas a chegada de um novo e importante ator justificaria sua reestruturação em tais níveis. Além disso, somente depois de garantido o ambiente legal do uso mais rentável do espectro (telefonia), orquestrou-se como se daria a concessão das suas "sobras" (radiodifusão de baixa potência). Partindo para exemplos internacionais, mas sem precisar ir muito longe, a estratégia do presidente da Argentina, Maurício Macri, para derrubar a Ley de Medios foi "reformá-la" (principalmente nos aspectos do controle social da mídia) para dar conta das telecomunicações. Noutro vizinho, boa parte das judicializações contra a nova lei de meios uruguaia (SCA) partiu da filial local de uma empresa de telefonia (a espanhola Telefônica). O que se vê é o Estado preparando o ambiente mais seguro para as teles.

Os aperfeiçoamentos legais em radiodifusão comunitária - que só acontecem depois da pressão da sociedade civil - normalmente não dão conta dos desafios sociais e das transformações tecnológicas em curso. Uma postura crítica não deixará de perceber tal descompasso como ativo, não meramente fruto de uma obsolescência jurídica natural em relação aos avanços tecnológicos. Afinal, como afirma Paiva (1998), "a mídia hegemônica pode até aceitar a existência de outro modelo, desde que ele não implique na partilha das mesmas condições técnicas. Ou seja, democratizar a tecnologia é o que o grupo hegemônico tem, a todo custo, evitado colocar em prática" (p. 147).

Quando iniciamos nossa pesquisa acadêmica sobre rádios comunitárias, há 12 anos, ainda na iniciação científica, nos guiava uma pergunta, agora invertida e tornada resposta: não se trata somente de analisar o quanto a rádio comunitária está na rede telemática, mas o quanto da rede passa a estar na rádio comunitária depois desse encontro singular. Respondendo à pergunta do título do presente artigo, da disputa de conteúdo (rádio) à disputa pela infraestrutura (rede) não há sobreposição, mas soma.

Essa descoberta se verifica na análise sincrônica dos diferentes modos de ser das rádios comunitárias. Foquemos, por exemplo, nos novos caminhos tecnológicos acima citados, particularmente simbólicos por encarnarem o modo hegemônico de ação política na atualidade: ao traçarmos a sequência histórica de diferentes tipos que vão desde as redes virtuais (trocas entre rádios comunitárias e com a comunidade/atores sociais) até as redes 
comunitárias (estrutura de troca e cooperação de infraestrutura de rede, da qual a rádio comunitária é um nó colaborativo) notamos uma evolução ponto-ponto, ponto-muitos, muitosmuitos verificado na transição da comunicação linear para a comunicação em rede sem, contudo, anularem-se: a rádio comunitária continua veiculando os spots em direitos humanos de um centro de produção, faz o upload da sua reportagem no Radiotube, interage com o grupo de ouvintes no WhatsApp, abre seu Wi-Fi na estrutura wimesh local etc.. Se fizéssemos o mesmo exercício com outro agrupamento de possibilidades tecnológicas encontraríamos correspondência parecida, por exemplo, da webrádio (ponto-muitos) para o podcast (muitosmuitos) e (potencialmente) o rádio digital (muitos-muitos, se levarmos em conta a técnica do multiplex, ou seja, diversas emissoras transmitindo suas distintas programações, a partir de uma mesma frequência e torre transmissora). Afastando-nos do determinismo decorrente do emprego, mais acima, da palavra "evolução", o que queremos destacar é um processo de autonomização de estruturas comunicacionais e políticas que se deslocam de um foco na difusão/coordenação para uma maior promoção da troca/auto-organização.

O que parece se descortinar é um processo de busca por autonomia que vem desde o sujeito político/ação política contemporânea e desemboca/tensiona a esfera das estruturas comunicacionais: há um deslocamento desde o foco na difusão/coordenação para a maior valorização da trocalauto-organização. Trata-se do mesmo movimento ponto-ponto, pontomuitos, muitos-muitos verificado na transição da comunicação linear para a comunicação em rede. Além da autonomização, verificamos um aprofundamento da luta em seus territórios via novas tecnologias: as múltiplas ferramentas interativas têm acrescentado novos modos de sociabilidades e vinculações locais, reforçando os laços da rádio comunitária com a sua comunidade.

Ainda que a trajetória histórica das rádios comunitárias aponte nessa direção, o processo de autonomização não é espontâneo. Ao contrário, o que vemos (e veremos) são as máquinas de apropriação sistematicamente conterem, enquadrarem e redirecionarem cada nova ação expansiva. A partir de nossa pesquisa, fica claro que já não se trata de escolher entre uma ou outra plataforma tecnológica, mas adequá-las e combiná-las: frente à expropriação totalizante do capital, a demanda das comunidades (e da humanidade) deve ser por acesso e acessibilidade a todas as tecnologias..

\section{REFERENCIAS}


APARICIO, C. Entrevista sobre a AMARC. Santiago (Chile), 2015. Entrevista concedida a João Paulo Malerba em maio de 2015.

CRIAR BRASIL. Relatório anual do Radiotube (2015). Fevereiro de 2016. Mimeo.

GONÇALVES, F. R. Rádios livres: as controvérsias ainda pairam no ar? Uma análise antropológica das novas relações sociais de radiodifusão. Dissertação (Mestrado em Antropologia Social) - Faculdade de Filosofia e Ciências Humanas: UFMG, 2010.

DEISTER, J. Telefonia comunitária: uma nova possibilidade no setor da comunicação. In: MALERBA, J. P. C. e BROCK, N. Rádios comunitárias em tempos digitais!. Rio de Janeiro: AMARC Brasil, 2017.

GRAMSCI, A. Cadernos do Cárcere. V. 1 a 6. Rio de Janeiro: Civilização Brasileira, 2001.

HARDT, M. e NEGRI, A. Multidão. Rio de Janeiro: Record, 2012.

; ___. Império. Tradução de Berilo Vargas. Rio de Janeiro: Record, 2001.

JARDIM PINTO, C. R., A trajetória discursiva das manifestações de rua no Brasil (2013-2015). In: Lua Nova [online] 2017, núm. 100, enero-abril, 2017, pp. 119-155.

LAMAS, E. Entrevista sobre a AMARC. Santiago (Chile), 2015. Entrevista concedida a João Paulo Malerba em maio de 2015.

MALERBA, J. P. C.. Rádios comunitárias no limite: crise na política e disputa pelo comum na era da convergência. Tese (Doutorado em Comunicação e Cultura) - Escola de Comunicação: UFRJ, 2016.

Rádios comunitárias 2.0: propostas éticopolíticas de uma rede de redes. Dissertação (Mestrado) - Escola de Comunicação: UFRJ, 2009.

MARICATO, E. (et al). Cidades rebeldes: Passe Livre e as manifestações que tomaram as ruas do Brasil. São Paulo: Boitempo: Carta Maior, 2013.

PAIVA, R. O espírito comum: comunidade, mídia e globalismo. Petrópolis: Vozes, 1998.

PERUZZO, C. M. K. Conceitos de comunicação popular, alternativa e comunitária revisitados: reelaborações no setor. In: Palabra clave, vol. 11, no. 2. Bogotá, 2008, p. 367-379.

VIANNA, B. Mutirão para redes_A experiência de Fumaça. In: MALERBA, J. P. C. e BROCK, N. Rádios comunitárias em tempos digitais!. Rio de Janeiro: AMARC Brasil, 2017. 
Professor e jornalista, é doutor em Comunicação e Cultura pela Escola de Comunicação da Universidade Federal do Rio de Janeiro (ECO/UFRJ), mestre e bacharel pela mesma instituição. Atualmente é professor substituto na Universidade do Estado do Rio de Janeiro (UERJ) e pesquisador do Laboratório de Estudos em Comunicação Comunitária (LECC/UFRJ). É membro da Associação Mundial das Rádios Comunitárias (AMARC Brasil) e colaborador em projetos do CRIAR Brasil, organização não governamental que atua com comunicação popular e pelo direito humano à comunicação. Atualmente investiga as mutações tecnopolíticas das mídias comunitárias, estruturadas em torno da reivindicação pelo uso comum e comunitário da infraestrutura da rede, bem como suas implicações para o campo da Comunicação Comunitária.

\section{@ $\odot \Theta \odot$}

Esta obra está licenciado com uma Licença

Creative Commons Atribuição-NãoComercial-CompartilhaIgual 4.0 Internacional 